JOURNAL
PENELITIAN PENDIDIKAN IPA $\begin{gathered}\begin{array}{c}e-I S S N ~: 2407-795 X \\ p-I S S N ~: 2460-2582\end{array} \\ \begin{array}{c}\text { Vol 1, No, } 2 \\ \text { Juli } 2015\end{array} \\ \text { http://jurnal.unram.ac.id/index.php/jpp-ipa }\end{gathered}$

\title{
INDUKSI KALUS KACANG TANAH (Arachis hypogaea L.) VARIETAS KELINCI DENGAN PERLAKUAN 2,4-D DAN BAP
}

\author{
Ida Royani $^{1}$, Lalu Zulkifli ${ }^{2}$, Prapti Sedijani ${ }^{2}$ \\ Program Studi Magister Pendidikan IPA Program Pascasarjana Universitas Mataram ${ }^{123}$ \\ idaroyani709@yahoo.co.id
}

\begin{abstract}
Key Words
Induction of

callus, 2,4-D,

$B A P$, peanuts.

Abstract

Callus induction determines the successfulness of micropropagation through somatic embryogenesis. This research was conducted to determine the effect of 2,4-D and BAP on callus induction of peanut (Kelinci strain). Callus induction was done on MS medium, with the observed variables were of initiation time, diameter, texture and color callus. Statistical analysis showed that 2,4-D and BAP affect the initiation time, diameter, texture and color callus. The earliest initiation of callus formation was obtained from MS medium with the addition of $4 \mathrm{mg} / \mathrm{L} \mathrm{2,4-D.} \mathrm{The} \mathrm{diameter} \mathrm{of} \mathrm{the}$ largest callus obtained from MS medium with the addition of $3 \mathrm{mg} / \mathrm{L} \mathrm{2,4-D}+1 \mathrm{mg} / \mathrm{L}$ BAP. Callus color were affected by the treatment of 2,4-D and BAP, while callus texture was not affected by these treatmen, in which compact callus texture was not affected by these treatment, in which compact callus texture was observed in all treatments.
\end{abstract}

\begin{tabular}{|c|c|}
\hline Kata Kunci & Abstrak \\
\hline $\begin{array}{l}\text { Induksi kalus, } \\
\text { 2,4-D, BAP, } \\
\text { kacang tanah. }\end{array}$ & $\begin{array}{l}\text { Induksi kalus menentukan keberhasilan micropropagasi melalui embryogenesis } \\
\text { somatik. Telah dilakukan penelitian untuk mengetahui pengaruh 2,4-D dan BAP } \\
\text { terhadap induksi kalus kacang tanah varietas kelinci. Induksi kalus dilakukan pada } \\
\text { media MS, dengan variabel waktu inisiasi, diameter, tekstur dan warna kalus. Uji } \\
\text { statistik menunjukkan bahwa } 2,4-D \text { dan BAP berpengaruh terhadap waktu inisiasi, } \\
\text { diameter, tekstur dan warna kalus. Inisiasi tercepat diperoleh dari media MS dengan } \\
\text { penambahan } 4 \mathrm{mg} / \mathrm{L} 2,4-D \text { dan diameter kalus terbesar diperoleh dari media MS } \\
\text { dengan penambahan } 3 m g / L \text { 2,4-D }+1 \mathrm{mg} / \mathrm{L} \text { BAP. Ada pengaruh } 2,4-D \text { dan BAP } \\
\text { terhadap warna kalus; dan tidak berpengaruh terhadap teksktur kalus, tekstur kalus } \\
\text { yang kompak diamati pada semua perlakuan }\end{array}$ \\
\hline
\end{tabular}




\section{PENDAHULUAN}

Penggunaan kacang tanah yang semakin beragam mengakibatkan permintaan kacang tanah semakin meningkat dari tahun ke tahun. Sampai saat ini kebutuhan kacang tanah secara nasional belum dapat dipenuhi dari produksi dalam negeri. Menurut data BPS (Badan Pusat Statistik) tahun 2012, di setiap Provinsi di Indonesia menunjukkan realisasi impor kacang tanah telah mencapai 50.378 ton. Kebutuhan kacang tanah dalam negeri mencapai 799.194 ton sedangkan kemampuan produksi atau yang ditargetkan 706 ribu ton, masih ada kekurangan 92 ribu ton di Indonesia. Rendahnya produksi nasional kacang tanah, disamping karena luas areal untuk pertanian yang terus berkurang, juga karena produktivitasnya per satuan luas lahanmasih rendah. Hal ini diakibatkan oleh penggunaan benih yang bermutu rendah dan oleh adanya serangan penyakit.

Micropropoagasi melalui embrio somatik dapat berkontribusi dalam menyediakan bibit dengan jumlah banyak dalam waktu singkat, seragam, dan bebas penyakit.Pembentukan embrio somatik melalui beberapa tahap, yaitu: Tahap globular, Tahap hati, Tahap torpedo, tahap kotiledon, Tahap kecambah, dan Tahap planlet (Purnamaningsih,2003). Untuk jangka panjang, perbanyakan tanaman secara in vitro diharapkan dapat membantu mengatasi kesulitan penyediaan bibit kacang tanah secara konvensional (Srilestari,2005). Penggunaan teknik tersebut sangat tergantung pada keberhasilan setiap tahap dalam kultur jaringan. Micropropagasi melalui embrio somatik,misalnya sangat tergantung dari keberhasilan induksi dan pertumbuhan kalus sebagai materi yang diregenerasikan menjadi plantlet.

Zat pengatur tumbuh 2,4-D, auxin sintetik yang banyak digunakan untuk induksi kalus karena salah satu peran pada tanaman adalh untuk proliferasi sel, sedang BAP salah satu sitokinin yang selain berperan dalam pembelahan sel, juga terhadap perbesaran dan pemanjangan sel.

\section{BAHAN DAN METODE}

Penelitian dilaksanakan di Laboratorium Kultur Jaringan Tanaman, PPH-Narmada dari bulan juni - agustus 2014. Kacang tanah varietas kelinci didapatkan dari laboratorium penangkaran bibit PPH-Narmada, yang ditumbuhkan oleh peneliti dalam kondisi aseptik untuk menyediakanexplant daun yang steril. Untuk melihat pengaruh 2,4-D dan BAP 
padainduksikalus, percobaan dilakukan dengan rancangan acak lengkap (RAL) terdiri dari 20perlakuan dengan tiga kali ulangan.

Media yang digunakan adalah media Murashige and Skoog 1962 (MS) dimasukkan ke dalam botol kultur dan disterilisasi dengan autoklaf pada tekanan $1,5 \mathrm{~atm}$, suhu $121^{\circ} \mathrm{C}$ selama 15 menit, dan disimpan dalam ruangan dengan suhu kamar $23-28^{\circ} \mathrm{C}$. Sterilisasi biji kacang tanah terdiri dari 2 tahap sterilisasi yaitu sterilisasi tahap I merendam biji pada deterjen selama 10 menit kemudian dibilas dengan air yang mengalir. Sterilisasi tahap II dilakukan di laminar air flow, dengan merendam biji secara berturut-turut kedalam larutan alkohol $70 \%$ selama dua menit, clorox $20 \%$ selama 15 menit, clorox 10\% selama 10 menit dan selanjutnya dibilas tiga kali dengan aquadest steril. Eksplan daun yang sudah dipotong dari kecambah steril diletakkan dalam cawan petri steril, kemudian dipotong dengan ukuran $0,5 \times 0,5 \mathrm{~cm}$ dan ditanam pada medium kutur, satu potong eksplan setiap botol. Penanaman eksplan dilakukan pada LAFC dalam kondisi aseptik. Setelah penanaman selesai, botol media ditutup dengan menggunakan plastik dan diikat dengan karet gelang kemudian dilapisi menggunakan perekat plastik. Eksplan yang sudah ditanam (inisiasi) diletakkan di rak kultur dalam ruang inkubasi dengan suhu $18^{-} 20^{\circ} \mathrm{C}$, tanpa penyinaran lampu di rak kultur.

Kenormalan dan homogenitas data, dianalisis dengan Uji Kolmogorov Smirnov. Data yang berdistribusi normal dan homogen, dalam hal ini data mengenai hari munculnya kalus dilanjutkan dengan uji Anova. Data yang tidak normaldan tidak homogen (diameter kalus) dilanjutkan dengan uji Kruskal Wallis. Data mengenai tekstur dan warna kalus dianalisis menggunakan analisis deskriptif karena ada sebagian data yang tidak tercatat karena kontaminasi.

\section{HASIL DAN PEMBAHASAN}

\section{Hari munculnya kalus.}

Kalus paling cepat muncul teramati pada media MS dengan penambahan 2,4-D 4 mg/L tanpa BAP dengan rata-rata13,3 hari setelah inokulasi. Data disajikan pada Tabel 1. Perlakuan dengan penambahan 2,4-D yang dikomboinasi dengan BAP lebih lama dalam menginisiasi kalus, yakni 23,33 hari setelah inokulasi, lebih lama di banding pada media yang mengandung 2,4-D tanpa BA. Kalus yang paling lama muncul teramati pada medium MS dengan penamabahn BAP 0,5 mg/L, tanpa 2,4-D. Pemberian 2,4-D akan 
meningkatkan aktifitas pembelahan sel scara terus menerus sehingga kalus akan cepat terbentuk. Dapat dilihat pada Tabel 1.

Tabel 1. Hasil uji Tukey hari muncul kalus pada berbagai kombinasi pemberian 2,4-D dan BAP

\begin{tabular}{llllll}
\hline Konsentrasi & \multicolumn{5}{c}{ Konsentrasi $2,4-\mathrm{D}(\mathrm{mg} / \mathrm{L})$} \\
BAP(mg/L) & 0 & 1 & \multicolumn{1}{c}{2} & 3 & 4 \\
\hline 0 & - & $17,3333^{\text {bcde }}$ & $18,0000^{\text {de }}$ & $17,0000^{\text {bcde }}$ & $13,3333^{\text {a }}$ \\
0,5 & $22,3333^{\text {g }}$ & $21,3333^{\text {fg }}$ & $19,6667^{\text {defg }}$ & $20,0000^{\text {efg }}$ & $14,3333^{\text {ab }}$ \\
1 & $21,3333^{\text {fg }}$ & $19,3333^{\text {detg }}$ & $17,6667^{\text {cde }}$ & $16,6667^{\text {bcd }}$ & $14,6667^{\text {bc }}$ \\
2 & $19,0000^{\text {def }}$ & $18,6667^{\text {def }}$ & $16,6667^{\text {bcd }}$ & $17,6667^{\text {cde }}$ & $17,6667^{\text {cde }}$ \\
\hline
\end{tabular}

Keterangan: Angka-angka yang diikuti oleh huruf yang sama menunjukkan perbedaan yang tidak nyata menurut uji Tukey pada taraf $\alpha=5 \%$.

Hasil penelitian ini sesuai dengan hasil penelitian (Suryowinoto, 2014) dan sejalan dengan peran 2,4-D yang mempunyai potensi tinggi untuk proliferasi sel dengan meningkatkan laju pembelahan sel bahkan lebih tinggi dibanding dengan jenis auxin lain (Yelnititis, 2012). Sedangkan inisiasi kalus pada medium tanpa 2,4-D berjalan lambat kumungkinan karena tidak adanya tambahan 2,4-D eksogen yang membantu dalam meningkatkan daya aktifitas pembelahan sel (Alamsyah, 2002).

\section{Diameter Kalus}

Masing-masing perlakuan 2,4-D dan BAP terhadap diameter kalus memberikan pengaruh yang berbeda nyata, kalus yang terbentuk memiliki diameter yang berbeda untuk setiap perlakuan. Diameter kalus dari setiap perlakuan disajikan padaTabel 2.Diameter kalus terbesar diperoleh dari medium MS dengan penambahan $3 \mathrm{mg} / \mathrm{L}$ 2,4-D + $1 \mathrm{mg} / \mathrm{L}$ BAP yaitu 1,8 cm. Hal ini sesuai dengan penelitian (Marlin, 2012) pada pisang yang menunjukkan bahwa diameter kalus terbesar pada media dengan penambahan $2-4 \mathrm{mg} / \mathrm{L}$ 2,4-D + 1-2 BAP mg/L dalam sukrosa $30 \mathrm{mg} / \mathrm{L}$. Hal ini menunjukkan bahwa 2,4-D dan BAP bersinergi dalam memacu pertumbuhan kalus. Data dapat dilihat pada Tabel 2.

Tabel 2.Diameter kalus pada berbagai kombinasi pemberian 2,4-D dan BAP.

\begin{tabular}{|c|c|c|}
\hline \multicolumn{2}{|c|}{ Zat Pengatur Tumbuh } & Diameter Kalus \\
\hline BAP & $2,4-\mathrm{D}$ & (Rata-rata) \\
\hline 0 & 0 & - \\
\hline & 1 & 1,10 \\
\hline & 2 & 1,23 \\
\hline & 3 & 1,36 \\
\hline
\end{tabular}




\begin{tabular}{|l|l|l|}
\hline & 4 & 1,40 \\
\hline 0,5 & 0 & 1,33 \\
\hline & 1 & 1,30 \\
\hline & 2 & 1,20 \\
\hline & 3 & 1,13 \\
\hline & 4 & 1,43 \\
\hline 1 & 0 & 1,16 \\
\hline & 1 & 1,16 \\
\hline & 2 & 1,10 \\
\hline & 3 & 1,83 \\
\hline & 4 & 1,16 \\
\hline 2 & 0 & 1,36 \\
\hline & 1 & 1,23 \\
\hline & 2 & 1,43 \\
\hline & 3 & 1,26 \\
\hline & 4 & 1,60 \\
\hline
\end{tabular}

\section{Tekstur Kalus}

Tekstur kalus yang diperoleh dari penelitian ini semuanya bertekstur kompak.kalus kompak merupakan kalus yang tersusun atas sel-sel berbentuk nodular, dengan struktur yang padat dan mengandung cukup banyak air (Manuhara, 2001). Kalus kompak disebabkan adanya perbedaan kemampuan jaringan tanaman dalam menyerap unsur hara dan zat pengatur tumbuh dalam media inisiasi (Ibrahim, 2010). Pengaruh 2.4-D dan BAP terhadap tekstur kalus tidak berbeda nyata, pada penambahan 2,4-D tanpa BAP, tekstur kalus lebih besar dan padat, ini disebabkan karna fungsi 2,4-D meningkatkan aktifitas pembelahan sel secara terus menerus sehingga ukuran kalus akan lebih besar dan padat bila dibandingkan dengan kalus yang mengandung BAP tunggal. Penambahan BAP pada perlakuan akan memberikan tekstur yang lebih kecil dan lembek, karena BAP berfungsi untuk pertumbuhan tunas sehingga mempengaruhi perkembangan dan tekstur kalus.

Karakteristik kalus tergantung pada komposisi media kultur, zat pengatur tumbuh, dan jenis eksplan. Kalus kompak pada kacang tanah varietas kelinci dapat dilihat pada gambar 1.

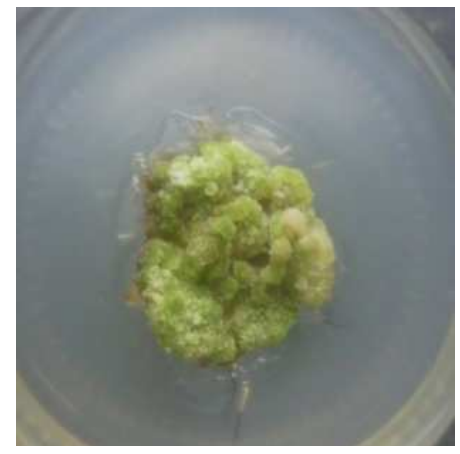


Gambar 1. Kalus kompak daun kacang tanah varietas kelinci.

\section{Warna Kalus}

Warna kalus merupakan warna yang timbul pada kalus karna adanya perbedaan perlakuan. Warna kalus pada kacang tanah varietas kelinci memiliki tingkatan warna yang berbeda mulai dari warna coklat, putih kecoklatan, putih kekuningan, dan putih kehijauan. Perbedaan warna kalus dipengruhi oleh penambahan 2,4-D dan BAP.Penambahan 2,4-D dengan konsentrasi lebih tinggi dari BAP akan memberikan warna putih, kecoklatan karna 2,4-D tidak dapat mengindikasikan kloropil, berbeda dengan penambahan BAP yang dapat mengindikasi klorofil sehingga mepengaruhi warna pada kalus yang cendrung berwarna putih kehijauan. Warna coklat pada kalus akibat dari semakin bertambahnya umur sel atau jaringan kalus, konsentrasi 2,4-D terlalu tinggi, kalus terlalu lama berada pada media tanam sehingga terjadi kekurangan unsur hara dan hormon tumbuhnya (Yusnita, 2004). Warna putih pada kalus menandakan sel-sel yang masih muda yang aktif membelah, warna putih kekuningan menunjukkan bahwa sel-sel yang dewasa menuju fase pembelahan aktif, warna coklat menunjukan gejala penuaan sel atau senesen. Perubahan warna kalus menjadi hijau, mengindikasikan terjadi perubahan fase kalus yaitu fase meristenoid (Widayanto, 2004). Contoh beberapa kalus dengan warnanya yang diperoleh dari penelitian ini disajikan dapat dilihat pada gambar 2 .

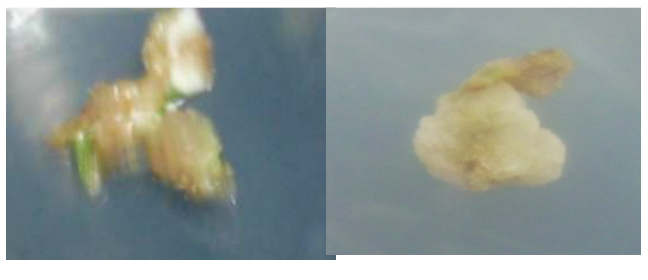

Coklat Putih Kecoklatan

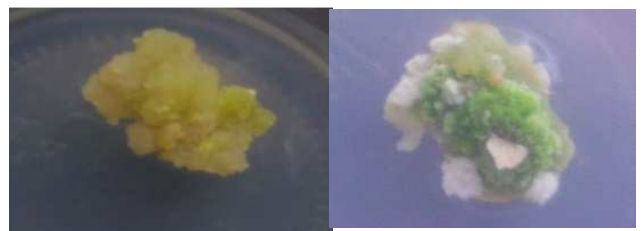

Putih Kekuningan Putih Kehijauan.

Gambar 2. Menunjukkan adanya variasi warna kalus kacang tanah varietas kelinci.

Kalus yang berkualitas adalah kalus yang berwarna hijau, warna kalus mengindikasikan keberadaan klorofil dalam jaringan, sehingga semakin hijau warna kalus semakin banyak kandungan klorofilnya (Fatmawati, 2008). Konsentrasi warna kalus berwarna putih kehijauan terdapat pada konsentrasi $2 \mathrm{mg} / \mathrm{L}$ BAPdan (0-4 mg/L) 2,4-D. Warna coklat terdapat pada medium MS dengan penambahan $0 \mathrm{mg} / \mathrm{L} \mathrm{BAP}+2 \mathrm{mg} / \mathrm{L}$ 2,4D. Warna kalus putih kekuningan terdapat pada medium dengan kombinasi(0,5-1 mg/L) 
$\mathrm{BAP}+(1-4 \mathrm{mg} / \mathrm{L})$ 2,4-D. Warna putih kecoklatan terdapat pada konsentrasi 0 BAP +2 mg/L 2,4-D. Semakin tinggi konsentrasi BAP akan memberikan warna hijau pada kalus, karna BAP sebagai sitokinin memacu pembentukan klorofil pada jaringan (Wartina, 2014).

\section{KESIMPULAN}

Zat pengatur tumbuh 2,4-D dan BAP berpengaruh terhadap waktu yang diperlukan untuk pembentukan kalus, diameter kalus dan warna kalus, tidak berpengaruh terhadap tekstur kalus. Kalus terbaik didapatkan dari medium MS yang ditambahkn 4 mg/L 2,4-D. Diameter kalus terbesar diperoleh pada medium MS yang ditambahkan 3 mg/L 2,4-D + 1 $\mathrm{mg} / \mathrm{L}$ BAP.

\section{DAFTAR PUSTAKA}

Alamsyah, S. 2002. Peranan Hormon Tumbuh Dalam Memacu Pertumbuhan Algae. Bogor. Institut Pertanian Bogor.

Badan Pusat Statistik. Luas Panen, Produksi dan Produktivitas Tanaman Kacang Tanah. 2009-2012 (online):http://www.bps.go.id/tab_sub/view.php?kat=3\&tabel=1\&daftar=1\&id_su byek=55\& otab=42,Diakses tanggal 6 Feberwari 2014 .

Fatmawati, A. 2008. Kajian Konsentrasi BAP dan 2,4-D Terhadap Induksi Kalus Tanaman Artemisia Annua. Tesis S2. Fakultas Pertanian UNS. Surakarta.

Ibrahim. 2010. Pengaruh Umur Eksplan Terhadap Keberhasilan Pembentukan Kalus Embriogenik Pada Kultur Meristem Jahe (Zingiber officinale Rosc). litri : 37-42.

Manuhara, Y.S.W. 2001. Regenerasi Tanaman Sawi (Brassica junceaL.var Morakot) Melalui TeknikKultur Jaringan. MIPA Universitas Airlangga:127-130

Marlin. 2012. Inisiasi Kalus Embrio Genetik pada Kultur Jantung Pisang`Curup` dengan Pemberian Sukrosa, BAP dan 2,4-D. Agrivigor :275-283

Rochiman. 2008. Perancangan Percobaan.Surabaya. Universitas Airlangga Press.

Srilestari. 2005. Induksi Embrio Somatik Kacang Tanah Pada Berbagai MacamVitamin Dan Sukrosa. Pertanian : 43-50.

Sugiyarto. 2014. Pengaruh 2,4-Diklorofenoksiasetat (2,4-D) dan Benzyl Aminipurin (BAP) Terhadap Pertumbuhan Kalus Daun Binahong (Anredera cordifolia L.) Serta Analisis Kandungan Flavonoid Total. Penelitian Saintek: 23-30. 
Purnamaningsih, R. 2003. Regenerasi tanaman melalui ebriogenesis somatik dan beberapa gen yang mengendalikannya. Buletin Agrobio : 51-58.

Wartina, R. 2014. Pengaruh NAA dan BAP Terhadap Regenerasi Kalus Kentang (Solanum tuberosum L.) Hasil Induksi Mutasi Ethyl Methane Sulponate (EMS). Tanaman Holtikultura : 1-9.

Widayanto. 2004. Pengaruh 2,4-D dan Kinetin Terhadap Pertumbuhan dan Perkembangan Eksplan "Serta Kandungan Metabolit Sekunder Kalus Jati Belanda (Guanzuma ulmifolia Lamk) Secara In Vitro. Tesis S2. Fakultas Pertanian Universitas Sebelas Maret.

Yelnititis. 2012. Pembentukan Kalus Remah dari EksplanDaun Ramin(Gonystylus Bancanus (Miq) Kurz.).Pemuliaan Tanaman Hutan: 181-119.

Yusnita. 2004. Kultur Jaringan Cara memperbanyak tanaman secara efisien. Jakarta: Agromedia Pustaka.

Zulkarnain. 2009.Kultur Jaringan Tanaman. Jakarta. Bumi Aksara. 